Thorax (1970), 25, 91.

\title{
Relevance of width of right descending branch of pulmonary artery as a radiological sign of pulmonary hypertension
}

\author{
V. TEICHM A N N, V. JEŽEK, F. HERLES \\ 2nd Medical Clinic, Faculty of General Medicine, Charles' University, Prague
}

\begin{abstract}
An enlargement of the diameter of the right descending branch (RDB) of the pulmonary artery in chest radiographs may serve as a sign of pulmonary arterial hypertension. We tried at first to establish exactly the normal values for men and women of different age, analysing the radiographs of 112 healthy subjects. There is a relationship of RDB diameter to sex and age. We compared the RDB diameters in 95 men suffering from chronic bronchitis with the pulmonary arterial pressure, flow, and resistance, and with the right ventricular work: a highly significant relationship of RDB diameter to all but the blood flow values was found. Considering (in men over 40 years of age) a diameter of the RDB of $18 \mathrm{~mm}$. or more as pathological, the reliability of the diagnosis of pulmonary hypertension in chronic bronchitis was $72.2 \%$ with readable films, or $64.2 \%$ when not reliably readable chest films were included. Nevertheless, a similar comparison in patients with mitral stenosis indicates that the radiographic picture of pulmonary hypertension differs according to the initial disease. Here we discuss the factors which may influence the RDB diameter.
\end{abstract}

Compensated chronic cor pulmonale in chronic bronchitis and its complications frequently escape diagnosis unless an elevated pulmonary artery pressure is found by right heart catheterization. Physical signs of hypertrophy of the right ventricle are rare in the initial stages of cor pulmonale in chronic bronchitis associated with hypoventilation, and electrocardiographic signs are rarely found at this time.

Radiological signs of pulmonary hypertension are more useful, as was proved by numerous authors who studied the radiological symptomatology of pulmonary hypertension (Assmann, 1920 ; Carmichael, Julian, Jones, and Wren, 1954 ; Dejdar, Widimský, Valach, Fejfar, and Bergmann, 1959 ; Van Epps, 1958; Goodwin, Cleland, Hunter, Davies, and Steiner, 1955 ; Healey, Dow, Sosman, and Dexter, 1949; Milne, 1963 ; Schwedel, 1946 ; Steiner, 1957 ; Teichmann, Dráb, Daum, and Ouředník, 1961). The signs which may be related to pulmonary hypertension are enlargement of the right ventricle, enlargement of the main trunk of the pulmonary artery, enlargement of the hilar branches of the pulmonary artery, in particular of the right descending branch (described also as truncus intermedius or arteria intermedia), narrowing of branches of the peripheral arterial bed, and pulsation of the hilar arteries. We think that some of these signs are not frequent in pulmonary hypertension, or depend too much on the subjective evaluation of the physician, or appear only in heart failure (Teichmann and Dráb, 1963). There is general agreement that the most useful radiographic sign is the width of the shadow of the descending branch of the right pulmonary artery (RDB).

To elucidate the diagnostic importance of the RBD, we investigated the relation between its diameter and any pulmonary hypertension. We compared catheterization data with the width of the RDB and we tried to find out the difference, if any, between the radiographic appearance of pulmonary hypertension in chronic bronchitis and in other diseases. In a group of healthy subjects we ascertained the diameter of the RDB to define more accurately the borderline between normal and pathological dimensions of the RDB.

\section{MATERIAL AND METHODS}

The chest radiographs were made at a target-film distance of $150 \mathrm{~cm}$. When the images of the RDB were not sufficiently reliable for the given purpose, tomograms of the hilar vessels were made. The transverse diameter of the RDB was measured in its 


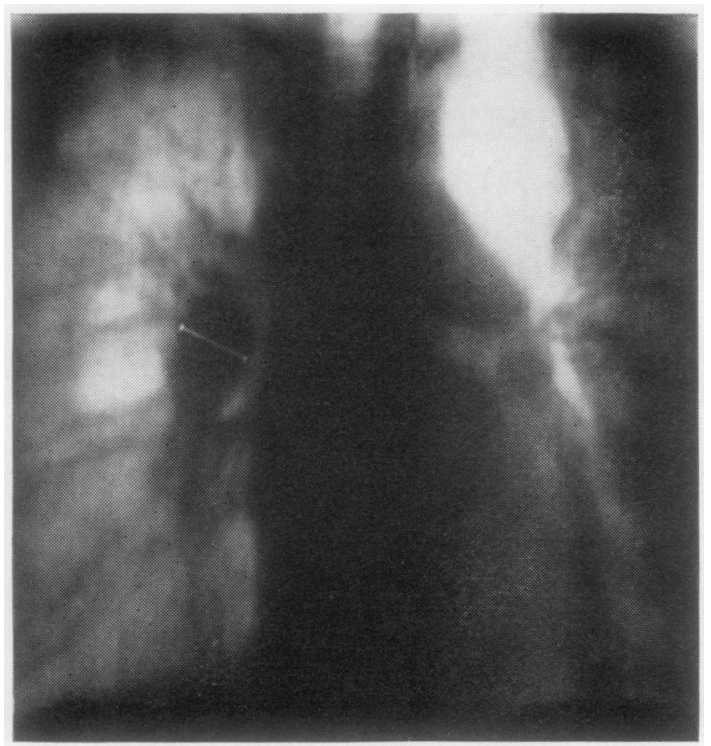

FIG. 1. Tomogram showing dilated $R D B$ and narrowing of peripheral arterial bed.

proximal portion at a distance up to $1 \mathrm{~cm}$. below the level of the right upper lobe bronchus (Fig. 1). Using tomographic examination, it is necessary to make allowance for the shorter target distance. The computation showed (Dejdar, 1961) that subtraction of $10 \%$ from the measured value is sufficiently accurate for practical purposes.

The pulmonary artery pressure was measured by the Hellige tensiometer. Mean pulmonary artery pressure exceeding 20 torr was considered to be elevated. The cardiac output was determined according to Fick's principle. The total pulmonary resistance and work of the right ventricle were calculated making use of the well-known formulae issuing from the pressure gradient and flow rate.

The significance of the relation between the size of the RDB and the pulmonary hypertension was checked by correlation coefficients according to Spearman (1904).

T A B L E I

NUMBER OF PATIENTS IN THE GROUPS EXAMINED

\begin{tabular}{|c|c|c|c|c|}
\hline & & & Male & Female \\
\hline $\begin{array}{l}\text { Normal subjects } \\
\text { Chronic bronchitis } \\
\text { Mitral stenosis }\end{array}$ & $\begin{array}{l}\ldots \\
\cdots\end{array}$ & $\begin{array}{l}\cdots \\
\cdots\end{array}$ & $\begin{array}{l}59 \\
95 \\
13\end{array}$ & $\begin{array}{l}53 \\
10 \\
13\end{array}$ \\
\hline
\end{tabular}

Altogether 142 patients were examined by radiography, and catheterization of the right heart was performed at about the same time (Table I). The main group consisted of 95 men with chronic bronchitis and its sequelae, 30 of them with signs of right heart failure. Eleven patients in whom it was not possible to measure the diameter of the RDB were not included in this group. Moreover 10 women suffering from the same disease were examined. For comparison a group of 26 patients with pulmonary hypertension and mitrial stenosis was examined. Then width of the RDB was compared with the mean ${ }^{\text {s }}$ pressure in the pulmonary artery, with the cardiace output and index, with the work of the right ven- tricle, and with the total pulmonary resistance.

A control group of healthy subjects comprised $5 \%$ men and 53 women. All were subjected to radio $\vec{x}$ graphic examination using the method mentioned above. None of them was catheterized.

\section{RESULTS AND THEIR ANALYSIS}

\section{HEALTHY SUBJECTS}

Statistical evaluation of relation between diameter of $R D B$ and age In this group we analysed the normal values of RDB in relation to age, sex, and body constitution. A highly significant relation was found between RDB diameter and the age of subjects examined in both the male $(r=0.480$ 응 $P<0.001, y=11.47+0.056 x)$ and female $(r=0.466$, $P<0.001, \quad y=10.01+0.049 x)$ groups. The data from patients with pulmonary hypertension were compared with those of healthy subjects of similar age. A statistical analysis was made separ ately for men and women under 40 and over $40 \mathrm{~g}$ years. Chronic bronchitis and its complications were found mainly in elderly subjects, whereas: mitral stenosis was in patients of younger age Taking the range of normal pathological valueso as the mean \pm 2 standard deviations, the firs约 pathological values in all groups of patients couldo be established (Table II).

T A B L E I I

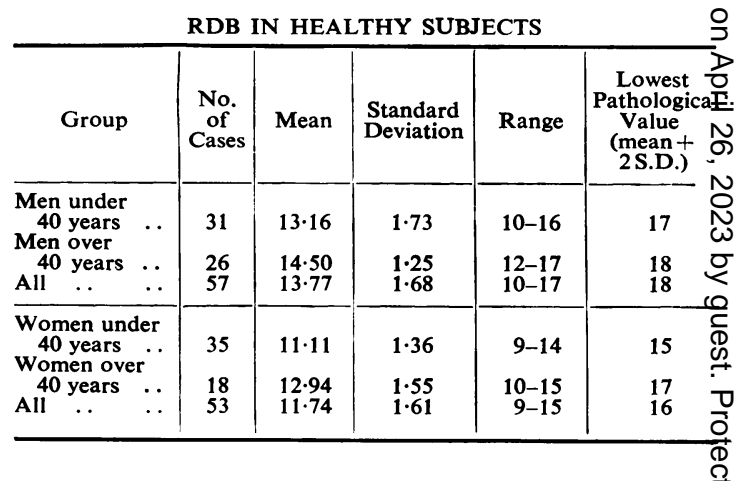

Comparison of diameter of $R D B$ in men and women The difference between men and womero was statistically significant in all healthy subjectş 
$(t=6.404, P<0.001)$ as well as in the group under 40 years $(t=3.786, P<0.01)$ and over 40 years $(\mathrm{t}=4.227, \mathrm{P}<0.001)$.

Statistical evaluation of relation between diameter of $R D B$ and height, body-weight, and body surface area In women the relation to weight was highly significant $(r=0.495, P<0.01)$ and to body surface area $(r=0.416, \mathrm{P}<0.01)$. In men there was no relation of the diameter of the RDB to height, body-weight, or body surface area. These results suggest that the differences between men and women are not due to constitutional factors, as they were found also in sub-groups with the same constitutional factor.

\section{MEN WITH CHRONIC BRONCHITIS AND COMPLICATIONS}

Comparison of diameter of $R D B$ with haemodynamic values The results of statistical evaluation are shown in Table III. There was a high statistical correlation between the diameter of the RDB and the mean pulmonary artery pressure at rest. On the other hand, there was no such relation between the diameter of the RDB and the blood flow through the pulmonary artery expressed as a cardiac output or index. The diameter of the RDB was also significantly related to the work of the right ventricle, but the closest relation was to the mean pressure in the pulmonary artery.

\section{T A B L E I I I}

RELATION BETWEEN DIAMETER OF RDB AND HAEMODYNAMIC FACTORS

RDB - mean pulmonary artery pressure $\quad \ldots \quad r=0.584, P<0.01$

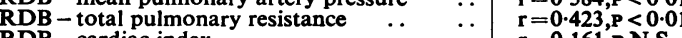

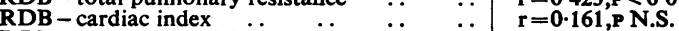

RDB - work of the right ventricle $\quad \ldots \quad \ldots .|r| r=0.493, P<0.01$

Relation of diameter of $R D B$ to mean pressure in pulmonary artery in particular groups of patients As is apparent from Fig. 2, the scatter of values was considerable despite the highly significant relation of the diameter of the RDB to the mean pressure in the pulmonary artery. This must be taken into account when establishing criteria of pulmonary hypertension in individual cases. Inasmuch as all the patients in the main group were men over 40 years of age and in view of the increase in the size of the RDB with age, we considered $18 \mathrm{~mm}$. as a first manifestation of pulmonary hypertension. The diameter of the RDB in chronic bronchitis was considerably enlarged $(18.31 \pm 2.96 \mathrm{~mm}$.). This value differs significantly

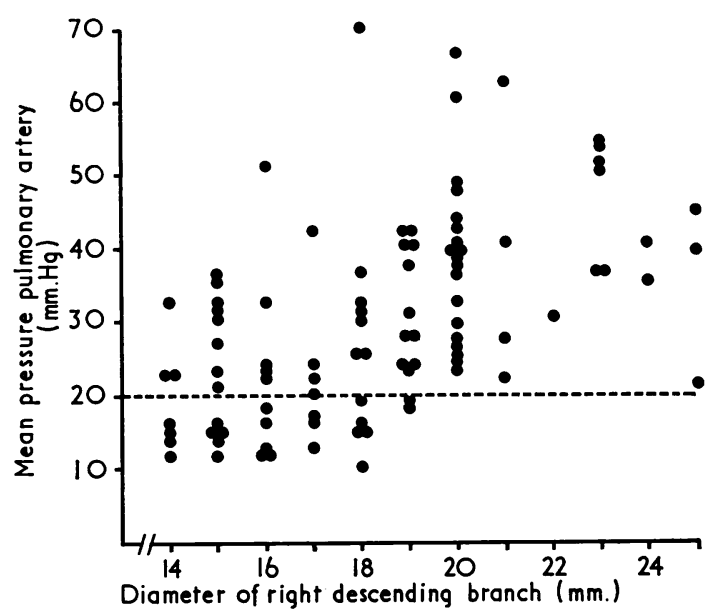

FIG. 2. Relation between mean pressure in pulmonary artery and diameter of $R D B$ in 95 men with chronic bronchitis.

from that for the total group of healthy men $(t=10.558, \quad P<0.001)$ and for the men over 40 years $(t=6.458, P<0.001)$.

Using this criterion in the group of men with chronic bronchitis and its sequelae, we found that pulmonary hypertension could be recognized in $72.2 \%$ of patients in this group (Table IV). A small diameter of the RDB, i.e., $17 \mathrm{~mm}$., cannot be set down as a critical value because it appears also in healthy subjects (among 23 patients with a normal pulmonary pressure it was found three times, i.e., in $13 \%$, while among 72 with pulmonary hypertension it was recorded four times, i.e., in $5.6 \%$ ). On the other hand, it would not be appropriate to use a greater diameter, e.g., $20 \mathrm{~mm}$., as a criterion. In our group of 72 patients with elevated pulmonary artery pressure this size was found in only 33 , i.e., $45 \%$. The diagnostic value of the signs studied would then be considerably reduced, even though false negative results could be excluded.

T A B L E I V

DIAGNOSTIC RELEVANCE OF DIAMETER OF RDB

\begin{tabular}{|c|c|c|c|}
\hline & & $\begin{array}{l}\text { No. of } \\
\text { Cases }\end{array}$ & Per cent \\
\hline $\begin{array}{l}\text { Correlation between diameter of RDB } \\
\text { and catheterization findings } \\
\text { Normal radiographic findings in } \\
\text { pulmonary hypertension } \cdots \\
\text { False radiographic diagnosis of } \\
\text { pulmonary hypertension } \cdots \\
\text { Correct radiographic diagnosis in } \ddot{72} \\
\text { pulmonary hypertensive patients }\end{array}$ & $\begin{array}{l}\cdots \\
\cdots \\
\cdots \\
\cdots\end{array}$ & $\begin{array}{r}68 \\
20 \\
7 \\
52\end{array}$ & $\begin{array}{r}71 \cdot 5 \\
21 \cdot 1 \\
7 \cdot 4 \\
72 \cdot 2\end{array}$ \\
\hline
\end{tabular}


As far as women are concerned, our group was too small to permit a detailed analysis and comparison. We can only state that of eight women with pulmonary hypertension none had an RDB narrower than $15 \mathrm{~mm}$. and that in women with values above $16 \mathrm{~mm}$. the pulmonary artery pressure was elevated in all. In those with an RDB of $15 \mathrm{~mm}$. or more, pulmonary hypertension was found in eight of nine patients, i.e., $89 \%$, and in those with an RDB of $16 \mathrm{~mm}$. or more, in $100 \%$.

PATIENTS WITH MITRAL STENOSIS In the group of 26 patients (men and women) with mitral stenosis the results were quite different. Having grouped the diameters of the RDB with regard to sex and age, as illustrated in Fig. 3, we found that the pathological values corresponded in all instances with pulmonary hypertension. On the other hand, pulmonary hypertension was present in patients with a normal RDB in $66 \%$ of the examined subjects. In some patients we found that the right ventricle was enlarged owing to the elevation of the pressure in the pulmonary artery. From what has been said, it is apparent that the assessment of the diameter of the RDB in mitral stenosis has in individual cases a very restricted diagnostic value, although the correlation of pathological signs of RDB with the pressure in the pulmonary artery is highly significant.

\section{DISCUSSION}

In evaluating the radiological pattern of pulmonary hypertension, it is essential to consider all the factors which may influence the diameter of the pulmonary arteries and especially of the RDB accessible to measurement in the radiographs. Several biophysical factors are involved, the influence of which may combine or be antagonistic (Fig. 4).

As for haemodynamic factors, in particular the following three are involved: the blood volume in the pulmonary arterial bed, the pulmonary blood flow, and pressure. Assessment of the first value in man is difficult. However, the others can be assessed readily during catheterization. Similar data to those we obtained on the relation between pressure in the pulmonary arteries and their diameter were obtained experimentally (Greenfield and Griggs, 1963 ; Harris, 1964). The relation between these two parameters was reliably proved; it is, however, not linear and indicates that other factors are involved. It is also known that the pulmonary vascular bed may become

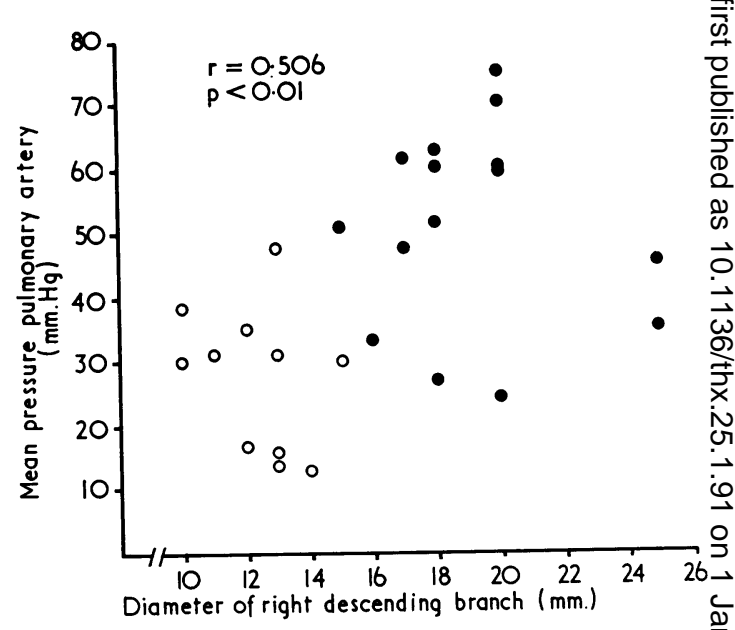

FIG. 3. Relation between mean pressure in pulmonary artery and diameter of $R D B$ in patients with mitrale stenosis; $O=$ normal values of diameter of $R D B$ correctedfor sex and age; $=$ pathological values of $R D B$.

dilated when the blood flow is abnormallyo increased even when the pressure in the pulmonary artery is normal. It was thus to be expected that part of the falsely positive or negative findings in our male patients with chronic bronchitis and itso sequelae could be explained in this way. But weö found no significant differences in the blood flow 3 (Table V).

\section{T A B L E V}

MEAN CARDIAC INDEX IN RELATION TO RADIOGRAPHIOU

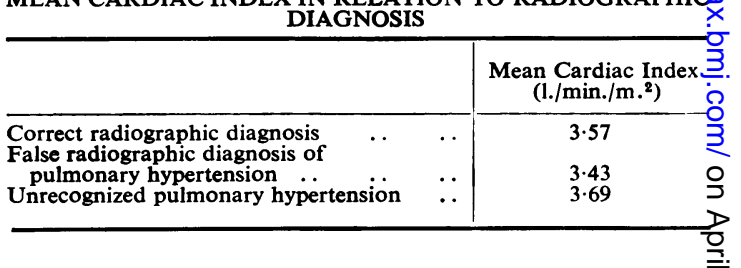

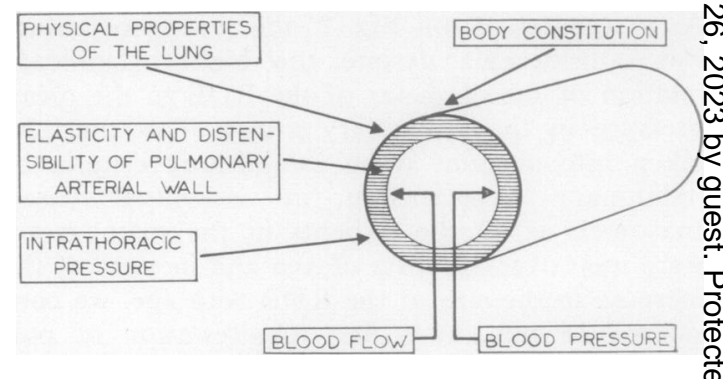

FIG. 4. Factors influencing the diameter of pulmonary vessels. 
Recently, increased attention has been devoted to the physical properties of the vascular wall, in particular to its elasticity and distensibility (Harris, 1964 ; Milnor, Jose, and McGaff, 1960 ; Patel, Schilder, and Mallos, 1960 ; Shaw, 1961). It appears that in this respect the properties of the vascular wall differ in healthy subjects and in patients with pulmonary hypertension. They may be related also to age and to the duration of pulmonary hypertension.

However, we have to take into account not only the physical properties of the pulmonary arteries but also the elasticity and the compliance of the surrounding pulmonary tissue, as well as the marked variations in the intra-thoracic pressure. Therefore we did not include in our group patients with isolated or predominating pulmonary fibrosis. According to our preliminary experience, the radiological image of the pulmonary arterial bed in pulmonary fibrosis differs from that in chronic bronchitis and lung emphysema.

As far as factors of sex, age, and constitution are concerned, they were analysed in healthy subjects. It was therefore possible to group the individual diameters with regard to sex and age prior to statistical evaluation. A similar approach was used by Hicken, Green, and Bishop (1968), who measured the 'transpulmonary arterial distance', and studied its relation to pulmonary arterial pressure. In healthy subjects the measurements of transpulmonary arterial distance were related to height but not to age or sex. This method may be useful in detecting chronic cor pulmonale in chronic bronchitis.

In mitral stenosis-contrary to the findings in chronic bronchitis and its sequelae-the conditions are different and more complicated. The differences may be interpreted in several ways: it is probably important that one half of the patients were women. We may also assume a haemodynamic factor as patients with mitral stenosis had on average a lower cardiac index than the patients with chronic bronchitis. A certain role may also be played by the blood volume in the lungs and its distribution in the pulmonary arteries and veins. However, we cannot rule out the influence of age-conditioned physical changes of the pulmonary arteries as the patients with mitral stenosis were younger than those with chronic bronchitis. Finally, we may assume that an important factor may be the duration and development of the basic disease (Teichmann and Dráb, 1963).

Our results as well as the observations of other authors show the complexity of the factors which bring about the change in the pulmonary arterial bed. A cross-sectional clinical analysis cannot solve all the revelant problems; its objective is to draw attention to the clinical value of radiography in the diagnosis of pulmonary hypertension, and to the circumstances which must be respected in its interpretation. A highly significant correlation between a diameter of the RDB of $18 \mathrm{~mm}$. or more and the elevated pressure in the pulmonary artery has great value in medical practice. It rendered possible the diagnosis of pulmonary hypertension originating from chronic bronchitis in $72 \%$ of the men examined. In women we were not able to reach any definite conclusions, the number of subjects examined being small. Our experience with mitral stenosis suggests that the diagnostic value of the diameter of the RDB in pulmonary hypertension of other origin may be quite different.

The high percentage of agreement between radiological signs and haemodynamic data in patients with chronic bronchitis and lung emphysema relates, of course, only to the patients in whom the measurement of the RDB was feasible. It is to be remembered that, in 11 instances out of the 106 men subjected to catheterization, it did not prove possible to differentiate and to measure the RDB: hence in $10.4 \%$ men examined we derived no diagnostic profit from radiography. The actual diagnostic yield of radiography in ascertaining pulmonary hypertension in men was reduced to $64 \cdot 2 \%$ of the cases examined.

\section{REFERENCES}

Assmann, H. (1920). Utber Veränderungen der Hilusschatten im Röntgenbilde bei Herzkrankheiten. Dtsch. Arch. klin. Med., 132, 335.

Carmichael, J. H. E., Julian, D. G., Jones, G. P., and Wren, E. M. (1954). Radiological signs in pulmonary hypertension. The significance of lines B of Kerley. Brit. J. Radiol., 27, 393.

Dejdar, R. (1961) Rentgenologie srdce a malého oběhu u nemocných plicni tuberkulosou. In Cor Pulmonale prí Tuberkulose, by Widimský et al., p. 61. Státnî zdravotnické nakladatelství, Praha.

_Widimsky, J., Valach, A., Fejfar, Z., and Bergmann, K. (1959). $X$-ray changes in cor pulmonale and their diagnostic significance. (In Czech.) Čas. Lék. čes., 98, 654.

Goodwin, J. F., Cleland, W. P., Hunter, J. D., Davies, L. G., and Steiner, R. E. (1955). Mitral valve disease and mitral valvotomy. Brit. med. J., 2, 573.

Greenfield, J. C., and Griggs, D. M. (1963). Relation between pressure and diameter in main pulmonary artery of man. J. appl. Physiol., 18, 557 .

Harris, P. (1964). Some physical properties of the walls of the human pulmonary artery. IV Congressus Cardiologicus Europeus (Abstracts), Prague.

Healey, R. F., Dow, J. W., Sosman, M. C., and Dexter, L. (1949). The relationship of the roentgenographic appearance of the pulmonary artery to pulmonary hemodynamics. Amer. J. Roentgenol., 62, 777 .

Hicken, P., Green, I. D., and Bishop, J. M. (1968). Relationship between transpulmonary artery distance and pulmonary arterial pressure in patients with chonic bronchitis. Thorax, 23, 446. 
Milne, E. N. C. (1963). Physiological interpretation of the plain radiograph in mitral stenosis, including a review of criteria for the radiological estimation of pulmonary arterial and venous pressure. Brit. J. Radiol., 36, 902.

Milnor, W. R., Jose, A. D., and McGaff, C. J. (1960). Pulmonary vascular volume resistance and compliance in man. Circulation, 22, 130 .

Patel, D. J., Schilder, D. P., and Mallos, A. J. (1960). Mechanical properties and dimensions of the major pulmonary arteries. J.appl. Physiol., 15,92.

Schwedel, J. B. (1946). Clinical Roentgenology of the Heart, p. 240. (Ann. Roentgenol., Vol. 18.) Paul Hoeber, New York.

Shaw, D. (1961). Pulmonary artery pressure wave analysis: a method for assessing pulmonary vascular elastic resistance. Brit. Heart J., 23, 461.
Spearman, C. (1904). The proof and measurement of association f? between two things. Amer. J. Psychol., 15, 72. Quoted by van det Waerden, B. L. (1957). Mathematische Statistik, p. 317. Springer, Berlin.

Steiner, R. E. (1957). Radiological appearances of the pulmonaryc vessels in pulmonary hypertension. Brit. J. Radiol., 31, 188.

Teichmann, V., and Dráb, K. (1963). X-ray picture of cor pulmonale

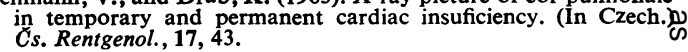

chronic cor pulmonale in chronic bronchitis and pulmonary emphysema. (In Czech.) Sborn. lék., 63, 158.

Van Epps, E. F. (1958). The roentgen manifestations of pulmonary hypertension. Amer. J. Roentgenol., 79, 241. 